\title{
A Conceptual Tool to Eliminate Filter Bubbles in Social Networks
}

\author{
Alireza Amrollahi \\ Macquarie Business School \\ ali.amrollahi@mq.edu.au
}

\section{Abstract}

Reliance on social media as a source of information has lead to several challenges, including the limitation of sources to viewers' preferences and desires, also known as filter bubbles. The formation of filter bubbles is a known risk to democracy. It can bring negative consequences like polarisation of the society, users' tendency to extremist viewpoints and the proliferation of fake news. Previous studies have focused on specific aspects and paid less attention to a holistic approach for eliminating the notion. The current study, however, aims to propose a model for an integrated tool that assists users in avoiding filter bubbles in social networks. To this end, a systematic literature review has been undertaken, and initially, 571 papers in six top-ranked scientific databases have been identified. After excluding irrelevant studies and performing an in-depth analysis of the remaining papers, a classification of research studies is proposed. This classification is then used to introduce an overall architecture for an integrated tool that synthesises all previous studies and offers new features for avoiding filter bubbles. The study explains the components and features of the proposed architecture and concludes with a list of implications for the recommended tool.

Keywords: filter bubble, social networks, prescriptive study, information bubble.

\section{Introduction}

According to a recent survey, the majority (36\%) of adults between 18 to 29 years in the USA consider social media their primary source of news (Shearer, 2018). Currently in Australia, six out of 10 people are using Facebook and an estimated 4.7 million Australians are actively using Twitter (Cowling, 2019), with 17\% of users trusting social media as their primary source of news (The Australia Institute, 2019). This reliance on social media and the way internet users seek information in this modern era have highlighted several interrelated risks and challenges. These challenges include the proliferation of fake news and misinformation, which has led to several disastrous incidents. Examples of such events include misguided beliefs about the COVID-19 outbreak and several violent incidents (Qureshi et al., 2020).

The spread of misinformation in social media or reflecting parts of the reality to convey an intended message have also been recognised as a method of recruitment for jihadist and extremist groups. The Australian Strategic Policy Institute identified the filter bubble as the fundamental phenomenon these groups use over social media to attract their supporters (Winter, 2016). However, using filter bubbles is not limited to ISIS and Islamist extremism. Previous studies have found that homogenous groups are more likely to become extreme in their thinking (Spohr, 2017). Therefore, a similar approach (deliberately or unintentionally) is used by other online extremist groups who convert genuine and factual news to emotionally charged, politically biased news (Rehm, 2017). Through this process, an angry or just curious member of society will turn to someone with extremist viewpoints or a member of radical 
groups. This is the case for the white racist groups in charge of the tragic incidents involving the Christchurch mass shooting in New Zealand (Purtill, 2019).

The notion of a filter bubble refers to the impact of our preferences and desires on the content and results we view on search engines, social media and other online platforms. This concept has been central to social media and internet research since it was developed by Eli Pariser (2011) and has been investigated by several scholars using various terms. Some of the terms used in the literature are information bubble (Liao \& Fu, 2013), [online] echo chamber (Möller et al. 2018), the personal ecosystem of information (Helberger, Kleinen-von Königslöw, \& van der Noll, 2015), partial information blindness (Haim, Graefe, \& Brosius, 2018) and information cocoons (Sunstein, 2007).

Several undesirable impacts have been mentioned in the literature for filter bubbles. In particular, there is a potential risk of narrowing the information sources for online users and "pushing users into the psychological comfort zone of self-confirmation and risking polarisation on a societal level" (Courtois, Slechten, \& Coenen, 2018, p. 2008). Increasing the risk of exposure to filter bubbles can create barriers to rational and diversified dialogue that is necessary for a democratic society. Therefore, the filter bubble has been recognised as a risk to a well-functioning democracy in modern society (Bozdag, 2015). Studies in various areas have also investigated the impact of filter bubbles on the polarisation of online debates (Flaxman, Goel, \& Rao, 2016; Seargeant \& Tagg, 2018) and extremism (Costello et al., 2016; Liao \& Fu 2013).

To avoid these negative impacts, several studies in the literature have recommended solutions to understand, avoid and decrease the negative impacts of filter bubbles. These studies are focused on various topics, including quantification of the bubble in social networks (Hannak et al., 2013), developing secondary apps (Wood et al., 2018) and approaches to stay anonymous to avoid filter bubbles (Ridgway, 2017). However, none of the studies in the literature, offer a comprehensive and integrated tool to help users avoid filter bubbles.

This study aims to focus on this shortcoming by integrating and synthesising the available solutions in the architecture for an integrated tool that can work as a viable design basis for an information system. By searching six scientific databases with related phrases, we attempted to systematically review the prescriptive literature and suggest an architecture for an integrated tool. We investigated these studies based on their aim and approach to avoid filter bubbles, use of technology and the effectiveness of the approach. The results of this research can help future research to find possible gaps in the literature and provide practitioners with a better understanding of the tools available to them for avoiding filter bubbles.

Section 2 of this paper provides a background to the concept of the filter bubble and posits the current study within the body of research. Section 3 introduces our methodology and approach for review and analysis of the literature. In Section 4, the suggested architecture is presented in section 4 , and results are discussed with possible implications for research and practice in Sections 5 and 6 . The paper concludes by explaining the contributions to the body of research. 


\section{Research Background}

\subsection{Filter bubble}

Although the notion of limiting sources of information to one's preferences has been largely studied in areas such as media (Jamieson \& Cappella, 2008) and psychology (Nickerson, 1998), the application of this notion to online and social media came under the spotlight after the development of the term filter bubble. In his book and subsequent talks (Pariser 2011), Eli Pariser (2011) focused on the impact of web personalisation and the way it affects our understanding about various topics when we refer to search engines as a source of knowledge.

Other studies then extended the concept to social media, as they discovered a similar mechanism is used in these platforms to recommend content and connections to people (Van Dijck \& Poell, 2013). The impact of social media on unpredicted outcomes of the 2016 USA election and the UK European Union membership (Brexit) referendum, brought the topic of fake news and filter bubbles to the fore (Allcott \& Gentzkow, 2017).

There are two main research streams on the filter bubble. The first stream (inspired by the work of Praiser) mainly focuses on the impact of recommendation systems (Divyaa, Tamhane, \& Pervin, 2018; Nguyen et al., 2014; Sanz-Cruzado \& Castells, 2018). These recommendation systems consider the user's demographic information, history and search behaviour in suggesting new content by social media and search engines, creating a filter bubble for the information the user receives.

This stream of research has been increasingly challenged by the second wave of studies that focuses on the role of social media users rather than recommendation system technologies (Garrett, 2017; Möller et al., 2018; Resnick et al., 2013). This perspective is supported by empirical research, including a study on Facebook content that found only $5 \%-8 \%$ of the content provided to people with various political viewpoints is based on their profile (Bakshy, Messing, \& Adamic, 2015). However, more recent events such as Facebook-Cambridge Analytica data scandal (Cadwalladr and Graham-Harrison 2018) and the widespread usage of bots on social networks to influence political campaigns (Lazer et al. 2018) indicated that the role of these platforms in creating filter bubbles could not be totally ignored.

Among previous studies, we found review research by Bozdag and van den Hoven (2015). The study considers two different perspectives about democracy (namely, a liberal view of democracy and deliberative democracy) and introduces several software designs that have been employed to combat the filter bubble. The study then suggests design criteria against filter bubbles based on the two models of democracy, and concludes that the reviewed tools 'do not define the filter bubble explicitly' and most of them "are performed for US politics" (Bozdag \& van den Hoven, 2015, p. 263). Except for this comparison of tools, we did not find any research that went beyond algorithmic enhancements of recommendation systems and investigated possible social concepts leading to the formation of filter bubbles and how the system can deal with these factors.

\subsection{Impacts of filter bubbles}

The negative consequences associated with filter bubbles are extensively studied in the literature. Some of these impacts can be directly associated with the filter bubble; for example, a decline in user trust (Nagulendra \& Vassileva, 2016), limiting people's access to information (Valdez, Kluge, \& Ziefle, 2018) and social fragmentation (Möller et al., 2018). This impact is 
particularly concerning when we consider how the content on social media is not subject to "significant third-party filtering, fact-checking, or editorial judgment" (Allcott \& Gentzkow, 2017, p. 211).

Another negative consequence that has been cited more specifically in the literature is the polarisation of political discussions in social media when people are trapped in a bubble that prevents them from receiving outsider information (Bakshy et al., 2015; Foth et al., 2016; Lahoti, Garimella, \& Gionis, 2018; Quraishi, Fafalios, \& Herder, 2018; Thonet et al., 2017; Yang et al., 2017). Previous literature has not found a significant relationship between exposure to an opposing political view and a change in people's political opinion (Bail et al., 2018). However, there are many studies that investigated the impact of filter bubbles on a commitment to a populist cause (Postill, 2018) and avoidance of cross-referencing (Van den Bulck \& Moe, 2018), which creates a risk to the diversity of opinions and well-functioning democracy as a result (Bozdag \& van den Hoven, 2015; Dylko et al., 2018).

Conversely, filter bubbles can indirectly impact or result in the proliferation of recent challenges in online media, including fake news (Bhatt et al., 2018; Seargeant \& Tagg, 2018), as they "amplify any content, from genuine, factual news to emotionally charged, politically biased news" (Rehm, 2017, p. 218). Social science studies have found that homogenous groups are more likely to become extreme in their thinking (Spohr, 2017), so the formation of these groups as a result of a filter bubble can lead to extremism. Finally, the negative impacts of filter bubbles have been studied in specific areas. For example, Taramigkou et al. (2013) investigated filter bubbles in music platforms and how they impact platform users' taste in music. Other researchers have studied the negative impacts of filter bubbles in areas such as online retail (Matt et al., 2014) and the source of information financial analysts receive (Shah et al., 2016). Table 1 summarises the negative consequences of filter bubbles.

\begin{tabular}{ll}
\hline \multicolumn{1}{c}{ Consequence } & \multicolumn{1}{c}{ Explanation } \\
\hline A decline in user trust & $\begin{array}{l}\text { Social media platforms provide no transparency about the mechanisms they } \\
\text { use to filter the content shown to the user. This lack of transparency, in the } \\
\text { long term, can result in the changes to the user's usage experience and a } \\
\text { decrease in their trust (Nagulendra \& Vassileva, 2016). }\end{array}$ \\
$\begin{array}{ll}\text { Limiting people's access to } \\
\text { information }\end{array}$ & $\begin{array}{l}\text { Users rely on a limited number of sources for news that are not subject to } \\
\text { professional editorial policies and are often ideologically biased (Allcott \& } \\
\text { Gocial fragmentation }\end{array}$ \\
$\begin{array}{l}\text { Gentzkw, 2017; Lahoti et al., 2018). } \\
\text { Filter bubbles result in a self-confirming feedback loop for users who are } \\
\text { subject to like-minded information. In the long term, this phenomenon will } \\
\text { create communities that become increasingly polarised and fragmented } \\
\text { (Möller et al., 2018). } \\
\text { Lack of access to factual news (from outside the bubble) results in the spread } \\
\text { of emotionally charged and biased news within the bubble, the credibility of } \\
\text { nhews }\end{array}$ & $\begin{array}{l}\text { Ideological polarisation through the filter bubbles in social media will help } \\
\text { the spread of extremist viewpoints (Spohr, 2017). }\end{array}$ \\
Extremism &
\end{tabular}

Table 1 - Negative consequences of filter bubbles

Despite the significant breakthroughs in the literature, previous studies are less focused on the long-term effects of filter bubbles. For example, although there are several studies on the impact of social networks on extremism (Awan, 2017; O'Callaghan et al., 2013; Spohr, 2017), 
no empirical studies have investigated the impact of filter bubbles and human authority on the formation of extremist groups.

\section{Research Method}

The current paper aims to suggest an architecture for an integrated tool that can deal with the problem of filter bubbles in social networks. To this end, a systematic literature review has been undertaken, and previous prescriptive studies on bursting filter bubbles have been reviewed. The following steps were used to conduct a systematic literature review, as suggested by Kitchenham and Charters (2007): (1) identifying resources, (2) study selection, (3) data extraction, (4) data synthesis, and (5) writing up the study as a report. These steps are frequently used in information system research to create rigour and transparency for literature review studies (Amrollahi, Ghapanchi, \& Talaei-Khoei, 2014; Paré et al., 2016). To follow these steps, we searched six scientific databases: Science Direct, Scopus, ProQuest, ACM Digital Library, Association for Information Systems electronic library, and Springer Link. Table 2 shows the final set of papers in each scientific database.

\begin{tabular}{lcc}
\hline \multicolumn{1}{c}{ Database } & First set of & \multicolumn{2}{c}{ Final set of } \\
papers & papers \\
\hline Association for Information Systems electronic library & 99 & 2 \\
Pro Quest & 119 & 5 \\
Science Direct & 19 & 8 \\
Scopus & 147 & 32 \\
Springer Link & 146 & 4 \\
ACM Digital Library & 41 & 20 \\
\hline Total & 571 & $\mathbf{7 1}$ \\
\hline
\end{tabular}

Table 2 - Distribution of the first/final set of papers in different databases

We searched for the following terms in title, keywords and abstracts, depending on the services offered by the relevant search engines: 'filter bubble' or 'information bubble' or 'social recommendation systems', 'social personalisation', 'news gatekeepers', 'information gatekeepers', 'personalised filtering', and 'online echo chamber'.

We started searching the related references with the above-mentioned set of keywords. Our initial search resulted in 571 papers. We then reviewed these initial pool of research studies first through reading abstracts and then the papers in full-text. In each of these stages, irrelevant and duplicated references were excluded. This review ended in the final pool of 71 papers. Table 3 illustrates the process through which we arrived at the final pool of research papers.

\begin{tabular}{lcc}
\hline \multicolumn{1}{c}{ Round } & $\begin{array}{c}\text { Number of papers } \\
\text { excluded }\end{array}$ & $\begin{array}{c}\text { Number of papers } \\
\text { remaining }\end{array}$ \\
\hline The initial list of papers & - & 571 \\
Exclusion based on the title & 107 & 464 \\
Exclusion based on abstract & 317 & 147 \\
Removal of duplicate papers & 9 & 138 \\
Exclusion based on full text (Final list) & 67 & 71 \\
\hline
\end{tabular}

Table 3- Different Stages of Inclusion / Exclusion and Number of Papers in Each Round 
For the current paper, we studied all articles in our final pool of papers with a focus on prescriptive research studies. The results of further analysis on the content of those papers are presented in the following sections. While the study focuses on the prescriptive approaches suggested in each article to prevent the formation of filter bubbles, there is less focus on the approach used to evaluate the rigour of research data or data analysis. Instead, we have concentrated on the robustness of the proposed approach and whether it can be applied in practice.

\section{Results}

The final set of papers formed the basis of the results described below. These final papers were studied in detail, and their recommendations on how to overcome the filter bubble phenomenon have been investigated. The results of this study helped us to distinguish two different perspectives in the reviewed studies on the filter bubble. Each of these perspectives is studied in further detail to understand and categorise their recommended approach.

There was a group of papers that proposed approaches to identify the filter bubble. This category includes identification of the bubble, confirming its existence, and quantification of the impact of the bubble. However, the second category of research studies is directly focused on approaches to take users out of the filter bubble or, as we call it in this paper, burst the bubble. Details about each category are explained below:

\subsection{Alert about the bubble}

Research studies under this category are focused on the identification and evaluation of filter bubbles. Filter identification studies are mainly focused on tools that check and alert users (in different ways) if they are trapped in a filter bubble. For example, Nagulendra and Vassileva (2014) proposed an interactive visualisation to enable the user to see the filtering. According to the authors, the tool has four goals: awareness, understanding, control of personalised filtering, and increasing the user's trust in the system. The tool has been implemented and tested on an independent platform.

The authors have extended this tool in their later work (Nagulendra \& Vassileva, 2016) to include both content and agent (users) in visualisation. This goal to detect the bubble has been continued in future studies using different approaches, including diffusion of topics (content) (TK, George, \& Thomas, 2015), network theory (agents) (Thonet et al., 2017) and machine learning (Lahoti et al., 2018).

Another stream of research on alerting filter bubble goes one step beyond bubble identification and considers evaluation and quantification of filter bubbles. For example, Hannak et al. (2013) developed a methodology for measuring personalisation in web search results. The proposed methodology compares different search results on Google considering the attributes of the agent (user) who performs the search. Also, Matakos, Terzi and Tsaparas (2017) developed an index to measure the tendency of opinion polarisation in network communities that can lead to the development of filter bubbles. This measure considers the opinion of agents (users) and the structure of the network.

Despite these studies and a few in-progress studies, no study has created a comprehensive framework for measuring the filter bubble. The proposed frameworks are mainly focused on the agent and less focused on the content. Finally, the proposed frameworks are less applied in real-time on social networks to show users the existence or significance of a filter bubble. 


\subsection{Burst the bubble}

This category of studies explains the suggested approach to disable or decrease the negative impact of recommendation systems that create a filter bubble by exploring new ideas and diverse perspectives. The first stream of research in this category is organised around bypassing or changing algorithms. For example, Ridgway (2017) suggests staying anonymous while being online as a solution to avoid potential filter bubbles. Conversely, Bozdag and van den Hoven (2015) reviewed possible design criteria proposed for bursting filter bubbles.

Another stream of research under this category is focused on bursting the bubble by extending users' awareness and encouraging them to explore different ideas. In this stream of research, again, the focus is on either new content or new agents. The majority of studies in our final pool are focused on viewing new content. Among them, the work of Taramigkou et al. (2013) is the first study we identified that proposed a methodology to help users explore new music genres outside their zone of interest. Webberley, Allen and Whitaker (2016) also suggested an algorithm for avoiding filter bubbles by focusing on the re-twitting behaviour of users rather than the scope of the user's social circle. Finally, several studies have suggested applications to enable users to view new content outside their preference (Linder et al., 2018; Wood et al., 2018).

However, recent studies have shifted the focus from content to the agent. Quraishi et al. (2018) proposed a graph-partitioning method that exploits social interactions to represent different viewpoints in a social network. A qualitative evaluation of the proposed method is also presented based on implementing it on a dataset retrieved from Twitter. Also, Sanz-Cruzado and Castells (2018) focused on contact recommendations and, based on the concept of weak connection, proposed an index for diversity. Despite the diversity of research studies in this category, a lack of focus on the real-time application of the proposed methods in social networks is observable among all the studies.

\section{Suggested Architecture}

Based on the outcome of our review, we propose an architecture for an integrated tool that can be implemented in social networks (regardless of the content type) to help avoid the formation of filter bubbles. Based on the outcome of our literature review, we propose two primary functions for this integrated tool: (1) alerting users about a potential filter bubble, and (2) bursting the bubble.

Under the alert component, the integrated tool first focuses on the identification of a filter bubble. Many social network users are not aware of the filter bubble they are kept due to a lack of transparency in the algorithms used by social networks (Bozdag \& Timmermans, 2011), so the tool needs to alert users. The cause of filter bubbles shifts from the recommendation algorithms to features enabling users to put themselves in a filter bubble (Amrollahi \& McBride, 2019), so it is important to also inform the users about the consequences of their actions. For example, users should have the right to see how blocking or muting one specific user may result in missing out on a network of users and their perspectives. Therefore, this bubble identification feature should be designed in connection with a bubble evaluation feature that assesses the significance of the bubble and also predicts future significance after certain events. 
Potential improvements in the recommendation systems have been suggested as a possible solution for bursting the bubble. However, in the current study, we have not considered this as a feature in the proposed architecture. Recommendation systems are not included in the tool for two reasons: (1) the architecture is proposed independent to the social network, type of content they provide, and the recommendation algorithm they use; and (2) the recommended integrated tool is focused on not only the recommendation algorithm but also on social network facilities that enable users to build a bubble around them. The architecture of the proposed integrated tool is illustrated in Figure 1.
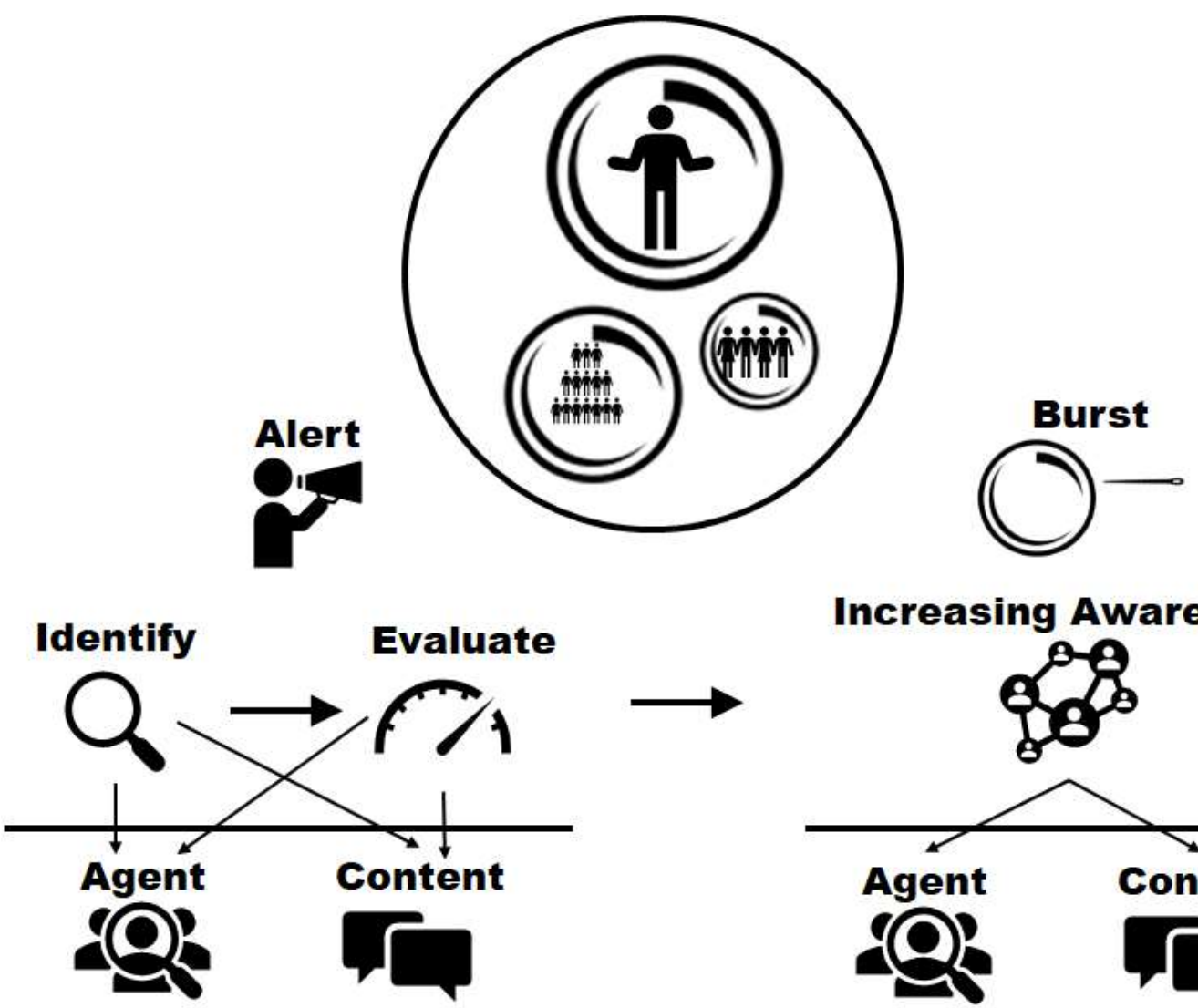

Increasing Awareness

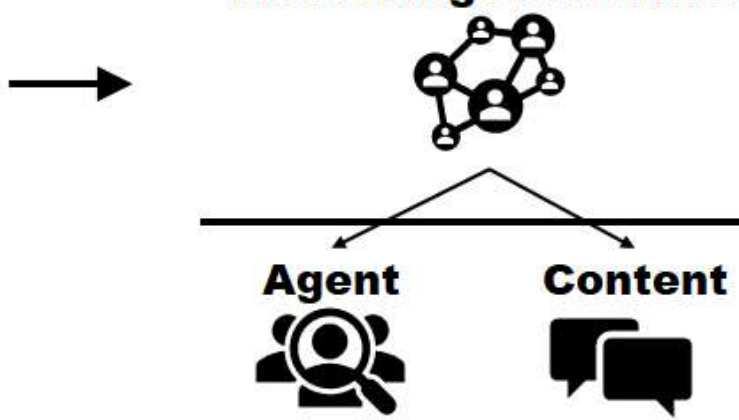

Figure 1 - The proposed architecture for an integrated tool

As illustrated in Figure 1, the proposed tool will focus on both agent and content. It means that to identify filter bubbles (as part of the alert component), both the connections of and content viewed by the user should be investigated. Also, the significance of the bubble should be evaluated by considering both the recommended content and recommended users. Finally, the awareness of users should be increased by suggesting both novel (out of bubble) content and connections. The next section discusses the implications of our findings for both research and practice.

\section{Discussion}

The results of our review indicate that studying the filter bubble phenomenon is an interdisciplinary research area. Our final pool of research studies includes work from areas ranging from information systems, information technology and management to political science, sociology, law and journalism. In the analysis of the related literature, we observed a focus on the content provided in social networks in few studies in various categories, while 
many others were focused on the users posting the content (agent) and how they impact the formation of filter bubbles.

In this study, we reviewed several negative consequences of filter bubbles. Table 4 revisits these negative consequences and explains how the proposed architecture can help in avoiding these consequences.

\begin{tabular}{|c|c|}
\hline Consequence & How it can be avoided using the proposed architecture \\
\hline A decline in user trust & $\begin{array}{l}\text { The architecture provides some level of transparency about the algorithms } \\
\text { used by social media platforms and the way they filter the content for users. } \\
\text { This transparency should give a sense of control to users and improve their } \\
\text { trust in the platform. }\end{array}$ \\
\hline $\begin{array}{l}\text { Limiting people's access to } \\
\text { information }\end{array}$ & $\begin{array}{l}\text { The architecture can show the user both the content and agents that have } \\
\text { been filtered for them. This feature will potentially enable users to refer and } \\
\text { visit those viewpoints. }\end{array}$ \\
\hline Social fragmentation & $\begin{array}{l}\text { The architecture potentially presents different viewpoints to a user by } \\
\text { increasing their awareness about 'outside the bubble' content. }\end{array}$ \\
\hline $\begin{array}{l}\text { The proliferation of fake } \\
\text { news }\end{array}$ & $\begin{array}{l}\text { The architecture permits more fact-checking and presents users with more } \\
\text { 'outside bubble' content, which decreases the chance for fake news to spread } \\
\text { within the bubble. }\end{array}$ \\
\hline Extremism & $\begin{array}{l}\text { The architecture can potentially show the legitimacy of the content and } \\
\text { increase a constructive discourse about news and information, preventing } \\
\text { the risk of biased and emotionally charged news getting over-spread. }\end{array}$ \\
\hline
\end{tabular}

Table 4 - How the proposed architecture can help users avoid the negative consequences of filter bubbles

The rest of this section explains the implications of the research for practice and research.

\subsection{Implications for practice}

Although the current study is based on the available academic literature, the outcome is presented in a way that can be implemented in practice. Designers and managers of social media platforms can benefit from the proposed architecture by seeing various avenues for improving their service or possible pitfalls in their social network that allows the formation of filter bubbles. For example, the architecture can direct them to various algorithms being used so they can present the significance of the filter bubble to their users. Implementation of tools like this will help social media platforms to improve the transparency of their mechanism and subsequently improve customers' trust in the platform (Nagulendra and Vassileva 2016).

The results can also benefit governments and policy-makers to regulate the operation of social networks. Governments should particularly focus on the role of filter bubbles in the spread of misinformation (including health-related misinformation) and investigate various approaches to increase community awareness about the filter bubbles. Furthermore, the performance of social networks in the systematic development of filter bubbles should be monitored, and regulatory actions should be taken to deal with them. The Burst and Alert components of the proposed architecture can benefit governments in this regard.

\subsection{Implications for research}

Although the proposed architecture in this study seeks to consider the various approaches for busting the filter bubble in the literature, it has not been put into practice as a solution in any social network. Therefore, we recommend future studies to consider this architecture as a basis 
and implement or evaluate it in social networks. Most of the components of the proposed tool have already been developed in the previous prescriptive studies. However, there are features that require further development in future research. Future studies can also focus on different parts of the proposed tool and develop algorithms for each part.

Specifically, the study proposes a real-time (predictive) bubble evaluation, which has not been directly studied and developed in previous studies. Various algorithms used in other areas such as semantic analysis (Hutchison, Daigle, \& George, 2018; Müller et al., 2016) and big data analytics (Weerasinghe et al., 2018) can be beneficial for future research to improve this feature. Moreover, the development and integration of the proposed tool with social networks can be a subject for future research.

Conversely, the current study does not provide evidence for the effectiveness of the proposed components of the system as a whole. Instead, it refers to the isolated studies used to suggest each component and various approaches they used to study the rigour and effectiveness of their research. Hence, future research should focus on the effectiveness of the proposed approach and check whether people in such filter bubbles will break free when given the opportunity. Both quantitative and qualitative methods can be used for the purpose of evaluation.

Finally, the results of the current study can inform future studies, especially future design research. In particular, future studies can use the proposed framework as a kernel theory to expand the results in the form of design theory (Gregor \& Jones, 2007). The available literature on areas such as sociology and psychology can benefit the design theory. For example, the initiation of filter bubbles has been studied in the sociology literature (Woon, 2018). Also, previous psychological studies can be used to investigate the motives and antecedents of selfconfirming behaviour that leads to the formation of filter bubbles (Mullainathan \& Washington, 2009) or attitude polarisation that strengthens them (Corner, Whitmarsh, \& Xenias, 2012).

\section{Conclusion}

Filter bubbles are problematic consequences of modern media and social networks as they create barriers to the rational and diversified dialogue that is necessary for a democratic society. Filter bubbles can develop in social networks as a result of users' confirmation bias, the structure of the network, the algorithms incorporated within the network, or a mixture of all the above (Bozdag et al. 2014; LR et al. 2018). This research, however, looks at filter bubbles as not only a product of recommendation algorithms in social networks but also a social issue that considers an active role for users building a filter bubble around them.

In the current paper, we proposed an architecture for an integrated tool that can be incorporated into social networks to prevent the formation of filter bubbles around users. This tool is proposed based on a systematic review of the literature and classification of the studies according to their aim. The proposed components of the integrated tool cover both liberal (through alert component) and deliberative (through awareness component) models of democracy (Bozdag \& van den Hoven, 2015). Moreover, by considering the identification and evaluation of filter bubbles and increasing users' awareness, the proposed architecture can be used against any type of filter bubble regardless of the source creating them. 
The results of our review show a lack of empirical studies on the effectiveness of the proposed tools. Even those studies that included their empirical results did so by using test data on developed hypothetical platforms. Therefore, the application of the proposed methods in social networks should be considered in future studies. This improvement in future research will lead to a better evaluation of the effectiveness of the proposed methods, which is another shortcoming we identified in the literature.

Based on the results of our literature review, the components of an integrated tool are proposed in the form of an architecture map. Unlike what is offered in the previous literature, our proposed method considers different perspectives on filter bubbles. These perspectives include a concurrent focus on alerting users to the formation of bubbles and bursting bubbles through increasing users' awareness. The proposed integrated tool also has a dual focus on both content and agent, which cannot be found in the previous literature.

\section{References}

Allcott, H., \& Gentzkow, M. (2017). Social media and fake news in the 2016 election. Journal of Economic Perspectives 31(2), 211-236.

Amrollahi, A., Ghapanchi, A. H., \& Talaei-Khoei, A. (2014). Three decades of research on strategic information system plan development. Communications of the Association for Information Systems 34(1), 84.

Amrollahi, A., \& McBride, N. (2019). How to burst the bubble in social networks? In 24th UK Academy for Information Systems international conference. Oxford, UK.

TK, A., George, K., \& Thomas, J. P. (2015). An empirical approach to detection of topic bubbles in tweets. 2015 IEEE/ACM 2nd international symposium on big data computing (BDC) (pp. 31-40). New York: IEEE.

Awan, I. (2017). Cyber-extremism: Isis and the power of social media. Society 54(2), 138-149.

Bail, C. A., Argyle, L. P., Brown, T. W., Bumpus, J. P., Chen, H., Hunzaker, M. F., ... Volfovsky, A. (2018). Exposure to opposing views on social media can increase political polarisation. Proceedings of the National Academy of Sciences 115(37), 9216-9221.

Bakshy, E., Messing, S., \& Adamic, L. A. (2015). Exposure to ideologically diverse news and opinion on Facebook. Science 348(6239), 1130-1132.

Bhatt, S., Joglekar, S., Bano, S., \& Sastry, N. (2018). Illuminating an ecosystem of partisan websites. arXiv preprint arXiv:1803.03576.

Bozdag, E., \& Timmermans, J. (2011). Values in the filter bubble ethics of personalisation algorithms in cloud computing. 1st international workshop on values in design-Building bridges between RE, HCI and ethics. Lisbon, Portugal.

Bozdag, E., Gao, Q., Houben, G.-J., and Warnier, M. (2014). Does Offline Political Segregation Affect the Filter Bubble? An Empirical Analysis of Information Diversity for Dutch and Turkish Twitter Users. Computers in human behavior 41, 405-415.

Bozdag, E., \& van den Hoven, J. (2015). Breaking the filter bubble: Democracy and design. Ethics and Information Technology 17(4), 249-265.

Bozdag, V. E. (2015). Bursting the filter bubble: Democracy, design, and ethics (Doctoral thesis). Delft University of Technology, Delft, Netherlands. 
Cadwalladr, C., and Graham-Harrison, E. (2018). Revealed: 50 Million Facebook Profiles Harvested for Cambridge Analytica in Major Data Breach. The Guardian 17, 22-23.

Corner, A., Whitmarsh, L., and Xenias, D. (2012). Uncertainty, scepticism and attitudes towards climate change: Biased assimilation and attitude polarisation. Climatic Change 114(3-4), 463-478.

Costello, M., Hawdon, J., Ratliff, T., \& Grantham, T. (2016). Who views online extremism? Individual attributes leading to exposure. Computers in Human Behavior 63, 311-320.

Courtois, C., Slechten, L., \& Coenen, L. (2018). Challenging Google search filter bubbles in social and political information: Disconforming evidence from a digital methods case study. Telematics and Informatics 35(7), 2006-2015.

Cowling, D. (2019). Social media statistics Australia-February 2019. Retrieved from https://www.socialmedianews.com.au/social-media-statistics-australia-february-2019/

Divyaa, L. R., Tamhane, A., \& Pervin, N. (2018). A clustering based social matrix factorisation technique for personalised recommender systems. Paper presented at the24th Americas conference on Information Systems, New Orleans, LA.

Dylko, I., Dolgov, I., Hoffman, W., Eckhart, N., Molina, M., \& Aaziz, O. (2018). Impact of customizability technology on political polarisation. Journal of Information Technology $\mathcal{E}$ Politics 15(1), 19-33.

Flaxman, S., Goel, S., \& Rao, J. M. (2016). Filter bubbles, echo chambers, and online news consumption. Public Opinion Quarterly 80(S1), 298-320.

Foth, M., Tomitsch, M., Forlano, L., Haeusler, M. H., \& Satchell, C. (2016). Citizens breaking out of filter bubbles: Urban screens as civic media. Proceedings of the 5th ACM international symposium on pervasive displays (pp. 140-147). New York: Association for Computing Machinery.

Garrett, R. K. (2017). The 'echo chamber' distraction: Disinformation campaigns are the problem, not audience fragmentation. Journal of Applied Research in Memory and Cognition $6(4), 370-376$.

Gregor, S., \& Jones, D. (2007). The anatomy of a design theory. Journal of the Association for Information Systems 8(5), 312-335.

Haim, M., Graefe, A., \& Brosius, H.-B. (2018). Burst of the filter bubble? Effects of personalisation on the diversity of Google News. Digital Journalism 6(3), 330-343.

Hannak, A., Sapiezynski, P., Molavi Kakhki, A., Krishnamurthy, B., Lazer, D., Mislove, A., \& Wilson, C. (2013). Measuring personalisation of web search. Proceedings of the 22nd international conference on world wide web (pp. 527-538). New York: Association for Computing Machinery.

Helberger, N., Kleinen-von Königslöw, K., \& van der Noll, R. (2015). Regulating the new information intermediaries as gatekeepers of information diversity. Info 17(6), 50-71.

Hutchison, P. D., Daigle, R. J., \& George, B. (2018). Application of latent semantic analysis in AIS academic research. International Journal of Accounting Information Systems 31, 83-96.

Jamieson, K. H., \& Cappella, J. N. (2008). Echo chamber: Rush Limbaugh and the conservative media establishment. Oxford: Oxford University Press. 
Kitchenham, B. A., \& Charters, S. (2007). Guidelines for performing systematic literature reviews in software engineering (EBSE Techinical Report). Durham, UK: University of Durham.

Lahoti, P., Garimella, K., \& Gionis, A. (2018). Joint non-negative matrix factorisation for learning ideological leaning on Twitter. Proceedings of the 11th ACM international conference on web search and data mining (pp. 351-359). New York: Association for Computer Machinery.

Lazer, D. M., Baum, M. A., Benkler, Y., Berinsky, A. J., Greenhill, K. M., Menczer, F., Metzger, M. J., Nyhan, B., Pennycook, G., and Rothschild, D. (2018). The Science of Fake News, Science 359(6380), 1094-1096.

Liao, Q. V., \& Fu, W.-T. (2013). Beyond the filter bubble: Interactive effects of perceived threat and topic involvement on selective exposure to information. Proceedings of the SIGCHI conference on human factors in computing systems (pp. 2359-2368). New York: Association of Computer Machinery.

Linder, R., Stacy, A. M., Lupfer, N., Kerne, A., \& Ragan, E. D. (2018). Pop the feed filter bubble: Making Reddit social media a VR cityscape. 2018 IEEE conference on virtual reality and 3D user interfaces (VR) (pp. 619-620). Piscatawy, NJ: Institute of Electrical and Electronics Engineers.

LR, D., Tamhane, A., and Pervin, N. (2018). A Clustering Based Social Matrix Factorization Technique for Personalized Recommender Systems, Proceedings of the Twenty-fourth Americas Conference on Information Systems, New Orleans, USA.

Matakos, A., Terzi, E., \& Tsaparas, P. (2017). Measuring and moderating opinion polarisation in social networks. Data Mining and Knowledge Discovery 31(5), 1480-1505.

Matt, C., Benlian, A., Hess, T., \& Weiß, C. (2014). Escaping from the filter bubble? The effects of novelty and serendipity on users' evaluations of online recommendations. Paper presented at the 35th international conference on information systems, Auckland, NZ.

Möller, J., Trilling, D., Helberger, N., \& van Es, B. (2018). Do not blame it on the algorithm: An empirical assessment of multiple recommender systems and their impact on content diversity. Information, Communication \& Society 21(7), 959-977.

Mullainathan, S., \& Washington, E. (2009). Sticking with your vote: Cognitive dissonance and political attitudes. American Economic Journal: Applied Economics 1(1), 86-111.

Müller, O., Schmiedel, T., Gorbacheva, E., \& Vom Brocke, J. (2016). Towards a typology of business process management professionals: Identifying patterns of competences through latent semantic analysis. Enterprise Information Systems 10(1), 50-80.

Nagulendra, S., \& Vassileva, J. (2014). Understanding and controlling the filter bubble through interactive visualisation: A user study. Proceedings of the 25th ACM conference on hypertext and social media (pp. 107-115). New York: Association for Computing Machinery.

Nagulendra, S., \& Vassileva, J. (2016). Providing awareness, explanation and control of personalised filtering in a social networking site. Information Systems Frontiers 18(1), 145158.

Nguyen, T. T., Hui, P.-M., Harper, F. M., Terveen, L., \& Konstan, J. A. (2014). Exploring the filter bubble: The effect of using recommender systems on content diversity. Proceedings 
of the 23rd international conference on world wide web (pp. 677-686). New York: Association for Computing Machinery.

Nickerson, R. S. (1998). Confirmation bias: A ubiquitous phenomenon in many guises. Review of General Psychology 2(2), 175-220.

O'Callaghan, D., Greene, D., Conway, M., Carthy, J., \& Cunningham, P. (2013). The extreme right filter bubble. arXiv preprint arXiv:1308.6149.

Paré, G., Tate, M., Johnstone, D., \& Kitsiou, S. (2016). Contextualising the twin concepts of systematicity and transparency in information systems literature reviews. European Journal of Information Systems 25(6), 493-508.

Pariser, E. (2011). The filter bubble: What the internet is hiding from you. London: Penguin.

Pariser, E. 2011. “Ted Talks: Eli Pariser: Beware Online "Filter Bubbles"." Online Video (https://www.ted.com/talks/eli_pariser_beware_online_filter_bubbles)

Postill, J. 2018. Populism and social media: A global perspective. Media, Culture E Society 40(5), 754-765.

Purtill, J. (2019). Fuelled by a toxic, alt-right echo chamber, Christchurch shooter's views were $\begin{array}{lllll}\text { celebrated } \quad \text { online. } & \text { NewC } & \text { Retrieved }\end{array}$ https://www.abc.net.au/triplej/programs/hack/christchurch-shooters-views-werecelebrated-online/10907056

Quraishi, M., Fafalios, P., \& Herder, E. (2018). Viewpoint discovery and understanding in social networks. Proceedings of the 10th ACM conference on web science (pp. 47-56). New York: Association for Computing Machinery.

Qureshi, I., Bhatt, B., Gupta, S., \& Tiwari, A. A. (2020). Causes, symptoms and consequences of social media induced polarisation (SMIP). Information Systems Journal. Manuscript in preparation.

Rehm, G. (2017). An infrastructure for empowering internet users to handle fake news and other online media phenomena. International conference of the German Society for Computational Linguistics and Language Technology (pp. 216-231). New York: Springer.

Resnick, P., Garrett, R. K., Kriplean, T., Munson, S. A., \& Stroud, N. J. (2013). Bursting your (filter) bubble: Strategies for promoting diverse exposure. Proceedings of the 2013 conference on computer supported cooperative work companion (pp. 95-100). https://doi.org/10.1145/2441955.2441981

Ridgway, R. (2017). Against a personalisation of the self. Ephemera: Theory $\mathcal{E}$ Politics in Organization 17(2), 377-397.

Sanz-Cruzado, J., \& Castells, P. (2018). Enhancing structural diversity in social networks by recommending weak ties. Proceedings of the 12th ACM conference on recommender systems (pp. 233-241). New York: Association for Computer Machinery.

Seargeant, P., \& Tagg, C. (2018). Social media and the future of open debate: A user-oriented approach to Facebook's filter bubble conundrum. Discourse, Context $\mathcal{E}$ Media 27, 41-48.

Shah, D., Koneru, P., Shah, P., \& Parimi, R. (2016). News recommendations at scale at Bloomberg Media: Challenges and approaches. Proceedings of the 10th ACM conference on recommender systems (pp. 369-369). New York: Association for Computer Machinery. 
Shearer, E. (2018, 10 December). Social media outpaces print newspapers in the U.S. as a news source. Pew Research Center. Retrieved from https://www.pewresearch.org/facttank/2018/12/10/social-media-outpaces-print-newspapers-in-the-u-s-as-a-news-source/

Spohr, D. (2017). Fake news and ideological polarisation: Filter bubbles and selective exposure on social media. Business Information Review 34(3), 150-160.

Sunstein, C. (2007). Republic. Com 2.0. Princeton, NJ: Princeton University Press.

Taramigkou, M., Bothos, E., Christidis, K., Apostolou, D., \& Mentzas, G. (2013). Escape the bubble: Guided exploration of music preferences for serendipity and novelty. Proceedings of the 7th ACM conference on recommender systems (pp. 335-338). New York: Association for Computer Machinery.

The Australia Institute. (2019). ABC still Australia's most trusted news source. Retrieved from http://www.tai.org.au/content/abc-still-australia-s-most-trusted-news-source

Thonet, T., Cabanac, G., Boughanem, M., \& Pinel-Sauvagnat, K. (2017). Users are known by the company they keep: Topic models for viewpoint discovery in social networks. Proceedings of the 2017 ACM conference on information and knowledge management (pp. 8796). New York: Association for Computer Machinery.

Valdez, A. C., Kluge, J., \& Ziefle, M. (2018). Elitism, trust, opinion leadership and politics in social protests in Germany. Energy Research \& Social Science, 43, 132-143.

Van den Bulck, H., \& Moe, H. (2018). Public service media, universality and personalisation through algorithms: Mapping strategies and exploring dilemmas. Media, Culture $\mathcal{E}$ Society 40(6), 875-892.

Van Dijck, J., \& Poell, T. (2013). Understanding social media logic. Media and Communication $1(1), 2-14$.

Webberley, W. M., Allen, S. M., \& Whitaker, R. M. (2016). Retweeting beyond expectation: Inferring interestingness in Twitter. Computer Communications 73, 229-235.

Weerasinghe, K., Pauleen, D., Scahill, S., \& Taskin, N. (2018). Development of a theoretical framework to investigate alignment of big data in healthcare through a social representation lens. Australasian Journal of Information Systems 22. https://doi.org/10.3127/ajis.v22i0.1617

Winter, C. (2016). An integrated approach to Islamic State recruitment. Canberra: Australian Strategic Policy Institute.

Wood, G., Long, K., Feltwell, T., Rowland, S., Brooker, P., Mahoney, J., ... Lawson, S. (2018). Rethinking engagement with online news through social and visual co-annotation. Proceedings of the 2018 CHI conference on human factors in computing systems (p. 576). New York: Association for Computer Machinery.

Woon, J. (2018). Primaries and candidate polarisation: Behavioral theory and experimental evidence. American Political Science Review 112(4), 826-843.

Yang, M., Wen, X., Lin, Y.-R., \& Deng, L. (2017). Quantifying content polarisation on Twitter. 2017 IEEE 3rd international conference on collaboration and internet computing (CIC) (pp. 299-308). New York: IEEE. 
Copyright: (C) 2021 Amrollahi. This is an open-access article distributed under the terms of the Creative Commons Attribution-NonCommercial 3.0 Australia License, which permits noncommercial use, distribution, and reproduction in any medium, provided the original author and AJIS are credited.

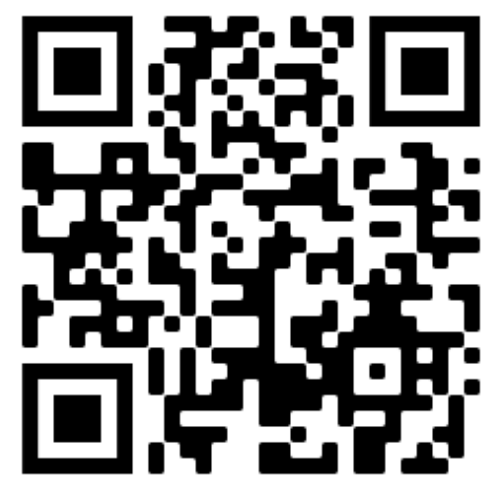

